\title{
Pyrogenic and neuroinflammatory properties of zymosan and its potential as an alternative to live yeast in antipyretic drug testing
}

\author{
Rachael Dangarembizi ${ }^{\text {ab } \star}$, Christoph D. Rummel ${ }^{c}$, Joachim Roth ${ }^{c}$, Kennedy H. Erlwanger ${ }^{\text {, }}$ \\ Michael T. Madziva ${ }^{d}$, and Lois M. Harden ${ }^{a}$ \\ ${ }^{a}$ Brain Function Research Group, School of Physiology, Faculty of Health Sciences, University of the \\ Witwatersrand, 7 York Road, Parktown, 2193 Johannesburg, South Africa; ${ }^{b}$ Department of Physiology \\ and Anatomy, Faculty of Medicine, National University of Science and Technology, P.O. Box AC 939, \\ Ascot, Bulawayo, Zimbabwe; ${ }^{c}$ Institute of Veterinary Physiology and Biochemistry, Justus Liebig \\ University Giessen, Frankfurter Strasse 100, D-35392 Giessen, Germany; ${ }^{\mathrm{d} S c h o o l}$ of Physiology, Faculty \\ of Health Sciences, University of the Witwatersrand, 7 York Road, Parktown, 2193 Johannesburg, \\ South Africa
}

* rachaeldangarembizi@gmail.com

\section{OPEN ACCESS}

Citation: Dangarembizi R, Rummel CD, Roth J, Erlwanger $\mathrm{KH}$, Madziva MT, and Harden LM. 2019. Pyrogenic and neuroinflammatory properties of zymosan and its potential as an alternative to live yeast in antipyretic drug testing. FACETS 4: | 62-1 82. doi: | 0.1 I 39/facets-20 | 8-0045

Handling Editor: Peter Zahradka

Received: November 6, 2018

Accepted: February 5, 2019

Published: May 23, 2019

Copyright: (C) 2019 Dangarembizi et al. This work is licensed under a Creative Commons Attribution 4.0 International License (CC BY 4.0), which permits unrestricted use, distribution, and reproduction in any medium, provided the original author(s) and source are credited.

Published by: Canadian Science Publishing

\section{Abstract}

Zymosan, an immunogenic cell wall extract of Saccharomyces cerevisiae has potential for use as an experimental pyrogen. However, the short-lived sickness responses noted with intraperitoneal and intra-articular administration of zymosan limits investigations on the long-term effectiveness of antipyretic drugs. Thus, there remains a need to establish an alternative route of zymosan administration that could induce long-lived fevers and inflammation. We injected male Sprague Dawley rats (250-300 g) subcutaneously with zymosan (30 or $300 \mathrm{mg} / \mathrm{kg}$ ) or saline; $n=7-8$. We measured core body temperature, cage activity, food intake and body mass for $24 \mathrm{~h}$ after injection. Blood and brain samples were collected at 2, 8, and $18 \mathrm{~h}$ after injection. Zymosan $(300 \mathrm{mg} / \mathrm{kg})$ induced fever, lethargy, and anorexia, which lasted for $24 \mathrm{~h}$. Zymosan-induced sickness responses were accompanied by increased blood plasma levels of interleukin (IL)- 6 and tumor necrosis factor (TNF)- $\alpha$; activation of inflammatory transcription factors (nuclear factor (NF) for IL-6, signal transducer and activator of transcription (STAT)-3, and NF- $\kappa \mathrm{B}$ ) in the hypothalamus and circumventricular organs; and increased hypothalamic mRNA expression of TNF- $\alpha$, IL- $1 \beta$, and IL- 6 and rate-limiting enzymes for prostaglandin synthesis. Our results confirm the suitability of subcutaneous administration of zymosan for screening antipyretic and anti-inflammatory drugs in rats.

Key words: cytokines, cyclooxygenase, anorexia, lethargy, immune-to-brain communication, circumventricular organs, Saccharomyces cerevisiae

\section{Introduction}

Brewer's yeast, derived from the yeast species Saccharomyces cerevisiae, is used for inducing pyrexia in pharmacological studies screening antipyretic drugs in rats (Vogel 2002; Thangaraj 2016). Injecting rats subcutaneously with Brewer's yeast dose-dependently induces prolonged fever, lethargy, anorexia, and body mass stunting (Dangarembizi et al. 2018). An increase in blood plasma levels of 
pro-inflammatory cytokines, hypothalamic mRNA expression of pro-inflammatory cytokines, and ratelimiting enzymes for prostaglandin synthesis accompany the sickness responses induced by Brewer's yeast administration (Dangarembizi et al. 2018). Activation of the inflammatory transcription factors, nuclear factor (NF)- $\mathrm{KB}$, NF- interleukin (IL)-6, signal transducer and activator of transcription (STAT)-3 and suppressor of cytokine signalling (SOCS)-3, likely control the synthesis and release of the inflammatory mediators associated with the sickness responses induced by Brewer's yeast administration (Rummel 2016; Dangarembizi et al. 2018). Despite the potential of Brewer's yeast to induce fever and inflammation, two responses required for antipyretic screening, there are some ethical considerations that may limit its use as a tool for routine antipyretic screening. These ethical considerations include the use of large volumes and doses of live yeast, which are associated with the development of an abscess and prolonged body mass stunting (Todd 1986; Dangarembizi et al. 2018). The animal research ethics principle of refinement states that procedures and techniques used for collecting data on experimental animals should be modified to minimize pain and distress, and to enhance the welfare of an animal used for research purposes (Baumans 2004). Thus, because of the potential animal welfare challenges associated with using live yeast as a pyrogen for routine antipyretic screening, there is a requirement to find an alternative fungal pyrogen that can induce reasonably long fevers that allow for antipyretic testing without causing unnecessary pain and suffering to the experimental animals.

Zymosan, an immunogenic cell wall extract of S. cerevisiae, has emerged as a potential fungal pyrogen to use in antipyretic testing as it can induce fever, anorexia, and lethargy in rats and mice (Gegout et al. 1994; Naoi et al. 2006; Kanashiro et al. 2009; Bastos-Pereira et al. 2014, 2017; Lima et al. 2017). Moreover, studies have shown that classic antipyretic (dipyrone and paracetamol) and antiinflammatory (ibuprofen, celecoxib, dexamethasone, and indomethacin) drugs are effective at attenuating zymosan-induced sickness responses (Naoi et al. 2006; Kanashiro et al. 2009; Bastos-Pereira et al. 2017). Although these findings provide support for the use of zymosan as a pyrogen in antipyretic drug testing, the short-lived (4-6 h) sickness responses noted with the intraperitoneal and intra-articular route of zymosan administration used to date limits investigations into the long-term effectiveness of antipyretic and anti-inflammatory drugs. Moreover, although studies have identified the inflammatory potential of zymosan by showing that intraperitoneal administration can induce an increase in circulating pro-inflammatory cytokines and prostaglandin $\mathrm{E}_{2}$ in cerebrospinal fluid, no study, to date, has fully characterized the inflammatory response induced in the brain following zymosan administration (Bastos-Pereira et al. 2014). Thus, for zymosan to be considered a viable pyrogen for antipyretic drug testing, we need to identify whether an alternative route of zymosan administration, such as the subcutaneous route, could induce longer-lived fever responses similar to those noted with subcutaneous administration of Brewer's yeast (Dangarembizi et al. 2018). Furthermore, we need to identify if the inflammatory response induced in the brain with zymosan parallels that noted with subcutaneous Brewer's yeast administration (Dangarembizi et al. 2018).

We have, therefore, chosen to determine the dose-dependent sickness and inflammatory responses induced by subcutaneous injection of zymosan. We measured pro- and anti-inflammatory mediators shown to be increased following subcutaneous administration of Brewer's yeast namely: transcription factors (NF- $\kappa B$, NF-IL6, STAT-3, and SOCS-3), pro-inflammatory cytokines (IL-6, IL-1 $\beta$, and TNF- $\alpha$ ) and enzymes involved in prostaglandin $\mathrm{E}_{2}$ synthesis (cyclooxygenase (COX)-2 and microsomal prostaglandin E synthase-1 (mPGES)). In terms of the inflammatory response, we focused on the circulation, brain endothelial cells, the hypothalamus, and the organum vasculosum of the lamina terminalis (OVLT), one of the three sensory circumventricular organs of the brain. Our rationale for focusing on these areas is that they have been previously identified as important in regulating sickness responses (for review see Roth and de Souza (2001) and Eskilsson et al. (2014)), and we have shown that subcutaneous administration of Brewer's yeast induces inflammation in these areas (Dangarembizi et al. 2018). Our results show that subcutaneous injection of $300 \mathrm{mg} / \mathrm{kg}$ of zymosan 
induced fever, lethargy, and anorexia, which lasted for $24 \mathrm{~h}$. An increase in circulating levels of pro-inflammatory cytokines, activation of inflammatory transcription factors, and an increase in the expression of cytokines and key prostaglandin-synthesizing enzymes in the hypothalamus and OVLT accompanied the sickness responses over $24 \mathrm{~h}$.

\section{Methods}

\section{Animals}

We obtained male Sprague Dawley rats from the National Health Laboratory Service (Johannesburg, South Africa) and housed the rats individually in acrylic cages lined with wood shavings in a temperature-controlled room $\left(22 \pm 2{ }^{\circ} \mathrm{C}\right)$ on a 12:12 h light/dark cycle (lights on at 0600). Rats received water and pelleted rat chow ad libitum and could acclimate to their environment for $7 \mathrm{~d}$ before surgery. On the day of injection rats had a body mass of between 250 and $300 \mathrm{~g}$. All experiments were performed in accordance with the principles of the Animal Ethics and Control Committee of the University of the Witwatersrand and were approved by its Animal Research Ethics Committee (ethics clearance number 2014/10/C). Animals were treated in accordance with the Guide for the Care and Use of Laboratory Animals (National Research Council 2010).

\section{Pyrogen administration}

We reconstituted zymosan A from S. cerevisiae (Z4250, lot number BCBP2641V, Sigma Aldrich, St. Louis, Missouri, USA) in $0.9 \%$ sterile, non-pyrogenic saline (Sabax, Johannesburg, South Africa). After reconstituting the zymosan in saline we vortexed the $30 \mathrm{mg} / \mathrm{mL}$ solution, placed it in a water bath at $37^{\circ} \mathrm{C}$ for $10 \mathrm{~min}$, and then sonicated it in $30 \mathrm{~s}$ intervals, with $10 \mathrm{~s}$ pauses in between for a total of $2 \mathrm{~min}$. Rats received a subcutaneous injection of the zymosan solution in the dorsum of the neck at a dose of either 300 or $30 \mathrm{mg} / \mathrm{kg}$; the volume injected was $10 \mathrm{~mL} / \mathrm{kg}$ of a $30 \mathrm{or} 3 \mathrm{mg} / \mathrm{mL}$ solution. We based the zymosan dose on a pilot study showing that subcutaneous administration of zymosan at a dose of $3 \mathrm{mg} / \mathrm{kg}$ did not induce fever and sickness behaviour in rats.

\section{Body temperature and cage activity}

As previously described by Hopwood et al. (2009), we measured core body temperature and cage activity of rats using sterile, wax-coated temperature-sensitive radiotelemeters (TA10TA-F40, Data Sciences, St. Paul, Minnesota, USA). We implanted the radiotelemeters intra-abdominally while the rats were under general anesthesia induced by an intramuscular injection of ketamine hydrochloride $(80 \mathrm{mg} / \mathrm{kg}$, Anaket-V, Bayer, South Africa) and xylazine (20 mg/kg, Chanazine, Bayer, South Africa) (Hopwood et al. 2009). After surgery, we gave the rats one intramuscular injection of an analgesic (Temgesic ${ }^{\circledR}$; Schering-Plough, Johannesburg, South Africa) and allowed them to recover for a week. The manufacturer (Data Sciences, St. Paul, Minnesota, USA) calibrated the radiotelemeters in a water bath at 35 and $39^{\circ} \mathrm{C}$ to an accuracy of $0.1{ }^{\circ} \mathrm{C}$.

\section{Body mass and food intake}

We measured body mass and food intake, using an electronic scale (Diamond, USA; accurate to $1 \mathrm{~g}$ ), $1 \mathrm{~h}$ before the start of the dark phase of the circadian cycle. Daily we filled the food containers with $200 \mathrm{~g}$ of standard rat chow and weighed the food remaining after $24 \mathrm{~h}$. Food intake was calculated by subtracting the food remaining in the food container from the initial $200 \mathrm{~g}$ provided. We corrected for food remaining on the cage floor.

\section{IL-6 and TNF- $\alpha$ bioassays}

As described previously by Ott et al. (2010), we performed a bioassay based on the dose-dependent growth stimulation of IL-6 on the B9 hybridoma cell line (Aarden et al. 1987) and on the cytotoxic 
effect of TNF- $\alpha$ on a mouse fibrosarcoma cell line WEHI 164 subclone 13 (Espevik and Nissen-Meyer 1986) to determine the level of IL- 6 and TNF- $\alpha$ in plasma (Ott et al. 2010). The detection limit of the assay, after considering the dilution of samples for the assays, proved to be 3 international units (IU) for IL- $6 / \mathrm{mL}$ and $6 \mathrm{pg} / \mathrm{mL}$ for TNF- $\alpha$.

\section{Tissue preparation}

For immunohistochemical analysis we cut coronal brain sections $(20 \mu \mathrm{m})$ at $-20{ }^{\circ} \mathrm{C}$ on a cryostat (2800 Frigocut-E, Cambridge Instruments, Germany) and thaw-mounted the sections onto poly-L-lysine-coated glass slides. The brain sections we used in this study were prepared from areas encompassing the OVLT $(0.40-0.60 \mathrm{~mm}$ bregma) according to the stereotactic atlas of the rat brain (Paxinos and Watson 2006). We collected 12 coronal brain sections per rat for immunohistochemical analysis and then thaw-mounted 35 consecutive frozen $30 \mu \mathrm{m}$ sections onto glass slides and dissected out the hypothalamus for RNA extraction. Thus, we used the same brains for immunohistochemical analysis and real-time PCR analysis. Following dissection, we stored the samples at $-55^{\circ} \mathrm{C}$ until processing.

\section{Immunohistochemistry}

\section{General procedure}

We air-dried the frozen brain sections for $10 \mathrm{~min}$ at room temperature and then fixed them for 10 min in 2\% paraformaldehyde (PFA; Merck, Darmstadt, Germany) diluted in phosphate buffered saline (PBS). After fixing the sections we washed them in PBS for $5 \mathrm{~min}$, three times, and then treated them with a blocking solution consisting of $10 \%$ normal donkey serum (NDS; Biozol, Germany) and Triton X-100 (0.1\% for NF-IL6 and $0.3 \%$ for COX-2 and STAT-3) for $1 \mathrm{~h}$ at room temperature. Table 1 shows the details of the primary antibody dilutions. We incubated the sections with the primary antibodies for $20-22 \mathrm{~h}$ at $4{ }^{\circ} \mathrm{C}$; the specificity of the respective antibodies has been previously tested (Rummel et al. 2006, 2011; Damm et al. 2011; Fuchs et al. 2013). After three 5-min washes in PBS, we incubated the sections for $2 \mathrm{~h}$ at room temperature with secondary antibodies conjugated with fluorescent dyes (Table 1 shows the details of the secondary antibody dilutions). To distinctly visualize the tissue surrounding the immunoreactive signal and to show the nuclear localization of the signal we counterstained the sections with nuclear 4,6-diamidino-2-phenylindole (DAPI) (1:8000 dilution in PBS; Mobitec GmbH, Göttingen, Germany) for 10 min. Finally, we cover-slipped (glass covers) all the sections with a glycerol/PBS solution (Citifluor, Ltd., London, UK) and stored the sections at $4{ }^{\circ} \mathrm{C}$ until microscopic analysis was performed.

\section{Colocalization}

To determine the contribution of endothelial cells to the NF-IL6, STAT-3, and COX-2 immunoreactive cell population we performed double immunohistochemistry. Before the first incubation, which lasted 20-22 h, we mixed the antibodies for NF-IL6, STAT-3, or COX-2 with the antibodies for von Willebrand factor (vWF), a marker for endothelial cells (dilutions given in Table 1). We visualized NF-IL6 and STAT-3 with Cy3-conjugated anti-rabbit IgG and COX-2 with Cy3-conjugated anti-goat IgG. Endothelial cell markers were visualized with Alexa-488-conjugated anti-rabbit or anti-sheep IgG (dilutions given in Table 1). In control experiments, the sections were incubated with the primary antibody mixture in which one of the primary antibodies was substituted with non-immunized animal IgG (goat IgG for COX-2, rabbit IgG for NF-IL6, and STAT-3). Inappropriate cross-reaction between antibodies was confirmed to be negligible.

\section{Microscopic analysis}

We acquired the images using a light/fluorescent microscope (Olympus BX50, Olympus Optical, Hamburg, Germany) with a black and white Spot Insight camera (Diagnostic Instruments, Visitron 
Table 1. Antibodies used for immunohistochemistry.

\begin{tabular}{|c|c|c|}
\hline Antibody & Dilution & Catalog number \\
\hline \multicolumn{3}{|l|}{ Primary antibodies } \\
\hline NF-IL6 rabbit polyclonal IgG & $1: 6000$ & $\begin{array}{c}\text { sc-150-G, Santa Cruz Biotechnology, Santa Cruz, } \\
\text { California, USA }\end{array}$ \\
\hline vWF rabbit polyclonal IgG & $1: 5000$ & 008202, Dako Deutschland, GmbH, Hamburg, Germany \\
\hline vWF sheep polyclonal IgG & $1: 2000$ & SARTW-IG, Affinity Biologicals, Ancaster, Ontario, Canada \\
\hline COX-2 goat polyclonal IgG & $1: 2000$ & $\begin{array}{c}\text { sc-1747, Santa Cruz Biotechnology, Santa Cruz, } \\
\text { California, USA }\end{array}$ \\
\hline STAT-3 rabbit polyclonal IgG & $1: 3000$ & sc-482, Santa Cruz Biotechnology, Santa Cruz, California, USA \\
\hline \multicolumn{3}{|l|}{ Secondary antibodies } \\
\hline Cy3-conjugated anti-rabbit IgG & $1: 600$ & $\begin{array}{c}\text { 711-165-152, Jackson Immuno Research, West Grove, } \\
\text { Pennsylvania, USA }\end{array}$ \\
\hline Cy3-conjugated anti-goat IgG & $1: 600$ & $\begin{array}{l}\text { 705-165-147, Jackson Immuno Research, West Grove, } \\
\text { Pennsylvania, USA }\end{array}$ \\
\hline Alexa 488-conjugated anti-rabbit IgG & $1: 500$ & AZA11055, MobiTec GmbH, Göttingen, Germany \\
\hline Alexa 488-conjugated anti-sheep IgG & $1: 500$ & AZA11015, MobiTec GmbH, Göttingen, Germany \\
\hline
\end{tabular}

Note: vWF, von Willebrand factor; NF-IL6, nuclear factor for IL-6; IgG, immunoglobulin G; STAT-3, signal transducer and activator of transcription-3.

Systems, Puchheim, Germany). The microscope had filter sets required for detection of the fluorescent conjugates Cy3, Alexa 488, and DAPI. For each staining and time point we took microphotographs in series with the same exposure times using MetaMorph 5.05 software (Molecular Devices Inc., Downingtown, Pennsylvania, USA). Using MetaMorph 5.05 software, we combined individual images to RGB colour images and optimized contrast and brightness of the images using Adobe Photoshop CC 2017 (Adobe Systems Incorporated, San Jose, California, USA). We undertook the staining and processing of all images the same way.

\section{Real-time PCR}

Following the manufacturer's instructions, we extracted total RNA from the hypothalamic sections (about $50 \mathrm{mg}$ of tissue) using TRIzol (Invitrogen, California, USA). We transcribed $1 \mu \mathrm{g}$ of total RNA into DNA using $50 \mathrm{U}$ murine leukemia virus (MULV) reverse transcriptase, $50 \mathrm{mmol} / \mathrm{L}$ random hexamers and $10 \mathrm{mmol} / \mathrm{L}$ dNTP mix (Applied Biosystems, Foster City, California, USA); the total reaction volume was $10 \mu \mathrm{L}$. After reverse transcription we did quantitative real-time PCR in duplicate using a preoptimized primer/probe mixture (Taqman Gene Expression Assay; Applied Biosystems) and Taqman universal PCR Master Mix (Applied Biosystems) using a StepOne Real-Time-PCR System (Applied Biosystems) (Damm et al. 2011). We normalized the cDNA quantities between different reactions by measuring the housekeeping gene $\beta$-actin (Applied Biosystems) as a reference. By subtracting the cycle threshold $(\mathrm{Ct})$ value for the housekeeping gene $\beta$-actin from the $\mathrm{Ct}$ value of the target gene, we calculated the $\Delta \mathrm{Ct}$ mean. Thereafter by subtracting the $\Delta \mathrm{Ct}$ mean for each sample from a control sample within the same experiment, we calculated the $\Delta \Delta \mathrm{Ct}$. The control sample was the sample with the max $\Delta \mathrm{Ct}$ mean, i.e., the lowest amount of the target gene. The relative quantification (RQ) was then calculated as $2^{-\Delta \Delta C t}$. The control sample therefore had an RQ of 1 and all other samples values represent an $\mathrm{x}$-fold difference to the control sample (Damm et al. 2011). 
The assay IDs for the analyzed genes are as follows: NF-IL6 (Rn00824635_s1), IKB $\alpha$ (Rn01473658_g1), SOCS-3 (Rn00585674_s1), COX-2 (Rn00568225_m1), mPGEs (Rn00572047_m1), TNF- $\alpha$ (Rn99999017_m1), IL-1 $\beta$ (Rn00580432_m1), and IL-6 (Rn01410330_m1).

\section{Experimental procedures}

\section{Experiment I}

Rats were assigned randomly to receive one of two different doses of zymosan $(300 \mathrm{mg} / \mathrm{kg}$ zymosan $(n=8), 30 \mathrm{mg} / \mathrm{kg}$ zymosan $(n=7))$, or saline $(n=7)$. All substances were injected at a volume of $10 \mathrm{~mL} / \mathrm{kg}$ body mass. We administered the injections at $1700,1 \mathrm{~h}$ before lights off at 1800 . We monitored core body temperature, cage activity, food intake, and body mass of the rats for $3 \mathrm{~d}$ before and $1 \mathrm{~d}$ after the subcutaneous injection.

\section{Experiment 2}

A different group of rats to those used in experiment 1 were assigned randomly to receive $300 \mathrm{mg} / \mathrm{kg}$ zymosan or saline, before blood and brain tissue was collected under terminal anaesthesia induced with an intraperitoneal injection of $1 \mathrm{~mL}$ sodium pentobarbital (Euthanase, $200 \mathrm{mg} / \mathrm{mL}$; Kyron Laboratories (Pty) Ltd., South Africa). For each of the intervention groups we euthanized rats to collect the blood and brain samples at 2, 8, and $18 \mathrm{~h}$ after injection. We euthanized four to six rats per time point for each of the intervention groups. The three time points we selected for sample collection are associated with the early phase $(2 \mathrm{~h})$ and plateau phase $(8$ and $18 \mathrm{~h})$ of the febrile response. We collected blood by cardiac puncture into sterile ethylene diamine tetraacetic acid (EDTA) tubes and centrifuged it at $3913 \mathrm{rcf}, 4^{\circ} \mathrm{C}$ for $10 \mathrm{~min}$. After the cardiac puncture, we perfused the rats' transcardially with ice-cold saline $(0.9 \%)$ for $2 \mathrm{~min}$. The whole brains we recovered were frozen on powdered dry ice for about $2 \mathrm{~min}$. We stored the blood plasma and brain tissue at $-80{ }^{\circ} \mathrm{C}$ until processing.

\section{Data analysis}

We showed all the data as mean and standard deviation (SD) and performed all statistical analyses with GraphPad Prism (version 7.0, GraphPad Software Inc., USA). Significance was set at $p<0.05$. For statistical purposes, we averaged the original 5-min temperature recordings over successive 2-h periods. The two-hourly temperature means were analyzed by two-way repeated measures analysis of variance (ANOVA) with intervention and time as main effects. We used a Bonferroni post hoc test to identify differences between groups when the ANOVA detected significant main effects or interactions. The 5-min nocturnal activity counts for each rat were summed for $12 \mathrm{~h}(1800-0600)$ and the summed values were averaged for three nights before the day of injection, when the rats were undisturbed in their home cages. Change in nocturnal cage activity was calculated as the difference between the night-time activity following injection and the average night-time activity during the three nights before injection and expressed as a percentage of the average pre-injection activity. Food intake was calculated as grams of food consumed in $24 \mathrm{~h}$ per $100 \mathrm{~g}$ of body mass and expressed as a percentage change from the average daily food intake measured over $3 \mathrm{~d}$ before injection. Change in body mass was determined by subtracting the body mass measured $24 \mathrm{~h}$ after the injection from the body mass measured immediately before the injection and expressed as the change in body mass ( $\mathrm{g}$ ) per $100 \mathrm{~g}$ of rat body mass. The changes in nocturnal cage activity, food intake, and body mass were analyzed by one-way ANOVA followed by a Bonferroni post hoc test. To determine whether the change in cage activity, food intake, and body mass after injection was significantly different from pre-injection values, a one-sample $t$ test was performed for each of the experimental groups. Cytokine levels and relative mRNA expression were compared by two-way ANOVA with treatment and time as main effects. We used a Bonferroni post hoc test to identify differences between groups 
when the ANOVA detected significant main effects or interactions. Where cytokine levels were undetectable, samples were assigned a value equivalent to the detection limit of the assay. Plasma cytokine data that were not normally distributed were log-transformed before statistical analysis. The cytokine bioassay data presented are non-transformed means and SD, but the associated significance values were derived from log-transformed data.

\section{Results}

\section{Experiment 1-Zymosan induces fever, lethargy, anorexia, and body mass stunting}

\section{Body temperature and nocturnal activity}

Figure 1 shows the core body temperature recorded over $1 \mathrm{~d}$ for rats that received subcutaneous injections of zymosan $(300$ or $30 \mathrm{mg} / \mathrm{kg})$ or saline. The main effects of time $\left(F_{(13,247)}=95.25, p<0.0001\right)$, treatment $\left(F_{(2,19)}=124.4, p<0.0001\right)$, and interaction $\left(F_{(26,247)}=40.41, p<0.0001\right)$ were significant such that rats injected with zymosan developed a fever, whereas rats injected with saline did not. Body temperatures of rats injected with $300 \mathrm{mg} / \mathrm{kg}$ zymosan started to increase significantly after a latent period of $2 \mathrm{~h}$ and peaked $9 \mathrm{~h}$ after injection at $38.95 \pm 0.23{ }^{\circ} \mathrm{C}$. Moreover, body temperatures of rats injected with $30 \mathrm{mg} / \mathrm{kg}$ zymosan started to increase significantly after a latent period of $4 \mathrm{~h}$ and peaked $6 \mathrm{~h}$ after injection at $38.56 \pm 0.25^{\circ} \mathrm{C}$. The magnitude and duration of the increase in body temperature was dependent on the dose of zymosan injected; between 8 and $24 \mathrm{~h}$ after injection, rats that received $300 \mathrm{mg} / \mathrm{kg}$ had significantly greater body temperatures compared with rats that received $30 \mathrm{mg} / \mathrm{kg}$ ( $p<0.01$, Bonferroni).

Figure 2 shows that subcutaneous injection of zymosan and saline both induced a significant decrease in nocturnal cage activity of rats over $12 \mathrm{~h}$ after injection, but the decrease following zymosan injection $(300 \mathrm{mg} / \mathrm{kg}, 59.4 \% \pm 10.6 \%$ and $30 \mathrm{mg} / \mathrm{kg}, 37.9 \% \pm 13.1 \%)$ was significantly greater than that following saline injection $(7.3 \% \pm 6.6 \%)$ (one-way ANOVA, $\left.F_{(2,19)}=46.58, p<0.0001\right)$. The magnitude of the decrease in nocturnal cage activity was dependent on the dose of zymosan injected as rats that

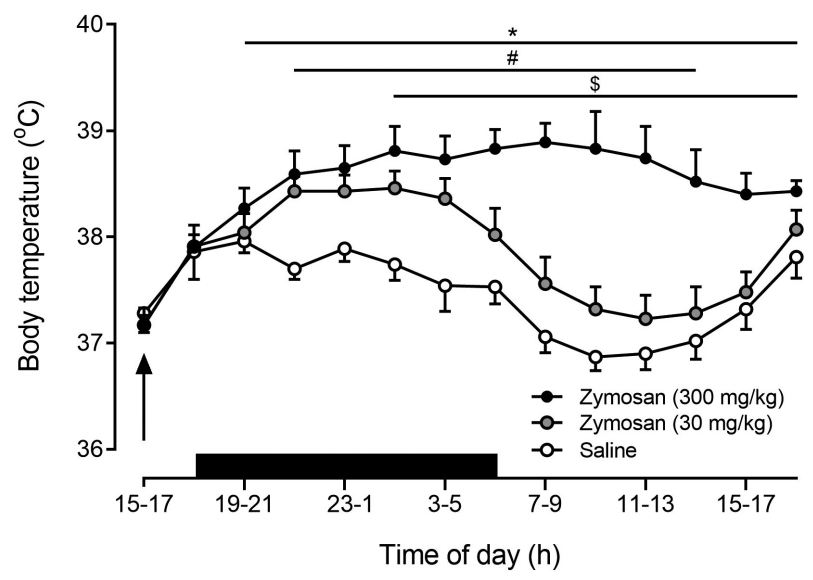

Fig. 1. Core body temperature (mean and standard deviation) of rats over $1 \mathrm{~d}$ following a subcutaneous injection of $300 \mathrm{mg} / \mathrm{kg}$ zymosan $(n=8), 30 \mathrm{mg} / \mathrm{kg}$ zymosan $(n=7)$, or saline $(n=7)$. The original 5 -min temperature recordings were averaged over $2 \mathrm{~h}$ and the two-hourly means have been plotted. The black arrow indicates injection time and black bars indicate lights off (1800-0600 clock time). ${ }^{*}$ indicates differences between $300 \mathrm{mg} / \mathrm{kg}$ zymosan and saline $(p<0.01$, Bonferroni). \# indicates differences between $30 \mathrm{mg} / \mathrm{kg}$ zymosan and saline $(p<0.05$, Bonferroni). \$ indicates differences between 300 and $30 \mathrm{mg} / \mathrm{kg}$ zymosan $(p<0.01$, Bonferroni). 


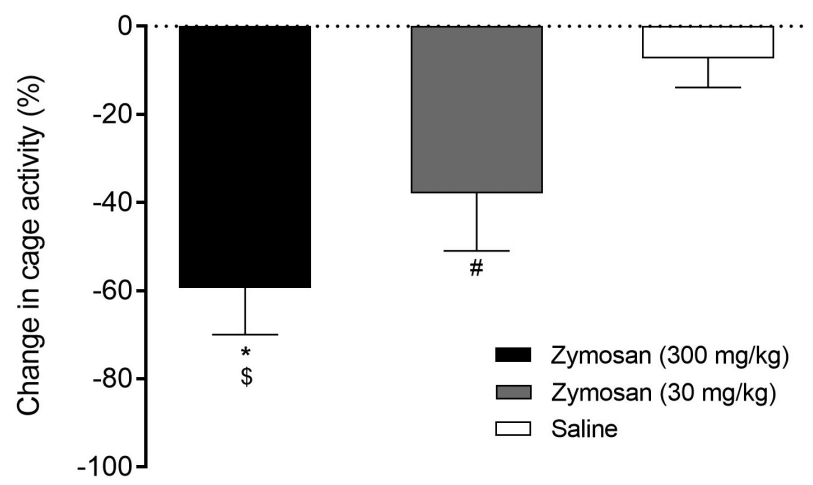

Fig. 2. Percentage change in nocturnal cage activity (mean and standard deviation) of rats over $12 \mathrm{~h}(1800-0600)$ after receiving a subcutaneous injection of $300 \mathrm{mg} / \mathrm{kg}$ zymosan $(n=8), 30 \mathrm{mg} / \mathrm{kg}$ zymosan $(n=7)$, or saline $(n=7)$. Change in nocturnal cage activity was calculated as the difference between the night-time activity following injection and the average night-time activity during the three nights before injection and expressed as a percentage of the average pre-injection activity. ${ }^{*}$ indicates differences between $300 \mathrm{mg} / \mathrm{kg}$ zymosan and saline $(p<0.0001$, Bonferroni). \# indicates differences between $30 \mathrm{mg} / \mathrm{kg}$ zymosan compared with saline $(p<0.0001$, Bonferroni). \$ indicates differences between 300 and $30 \mathrm{mg} / \mathrm{kg}$ zymosan $(p<0.01$, Bonferroni). A one sample $t$ test indicated that cage activity decreased significantly from pre-injection values in all groups (300 $\mathrm{mg} / \mathrm{kg}$, $t=15.9$, and $p<0.0001 ; 30 \mathrm{mg} / \mathrm{kg}, t=7.7$, and $p=0.0003$; saline $t=2.9$ and $p=0.03$ ).

had received $300 \mathrm{mg} / \mathrm{kg}$ decreased nocturnal cage activity by about $20 \%$ more than rats that had received $30 \mathrm{mg} / \mathrm{kg}(p<0.01$, Bonferroni).

\section{Food intake and body mass}

For the $3 \mathrm{~d}$ before receiving an injection the average daily food consumption of the rats per $100 \mathrm{~g}$ of body mass was $7.5 \pm 0.3 \mathrm{~g}$. The average body mass of the rats before the injection was $282 \pm 22 \mathrm{~g}$. Figure $3 \mathrm{~A}$ shows that subcutaneous injection of $300 \mathrm{mg} / \mathrm{kg}$ zymosan induced a significant decrease $(37.9 \% \pm 7.7 \%)$ in 24 -h food intake of rats compared with injection of saline (one-way ANOVA, $\left(F_{(2,19)}=45.09, p<0.0001\right)$. The food intake of rats that had received $30 \mathrm{mg} / \mathrm{kg}$ zymosan or saline was significantly different from the food intake of rats that had received $300 \mathrm{mg} / \mathrm{kg}$, but it was not significantly different from pre-injection values $(t=0.8, p=0.46$ and $t=0.7, p=0.52)$. Thus, the decrease in food intake induced by zymosan injection was dependent on the dose administered.

Figure $3 \mathrm{~B}$ shows that the decrease in food intake following subcutaneous injection of $300 \mathrm{mg} / \mathrm{kg}$ zymosan was associated with a loss of body mass (one-way ANOVA, $F_{(2,19)}=12.54, p=0.0003$ ). Over the $24 \mathrm{~h}$ period after injection there was no significant change in the body mass of rats that received $30 \mathrm{mg} / \mathrm{kg}$ zymosan $(t=1.2, p=0.29)$, whereas rats that received saline significantly gained $(1.1 \pm 0.8 \mathrm{~g})$ body mass $(t=3.3, p=0.02)$. Thus, the loss of body mass induced by zymosan injection was dependent on the dose administered.

\section{Experiment 2-Zymosan induces an inflammatory response in the periphery and the brain}

\section{Blood plasma levels of pro-inflammatory cytokines}

We collected blood plasma at 2, 8, and $18 \mathrm{~h}$ after subcutaneous administration of $300 \mathrm{mg} / \mathrm{kg}$ zymosan or saline. Figure 4A shows that rats injected with zymosan had significantly elevated blood plasma levels of TNF- $\alpha$ at $2 \mathrm{~h}$ after injection, compared with rats injected with saline (main effects of time $\left(F_{(2,23)}=20.42, p<0.0001\right)$, treatment $\left(F_{(1,23)}=30.64, p<0.0001\right)$, and interaction $\left(F_{(2,23)}=20.42\right.$, 

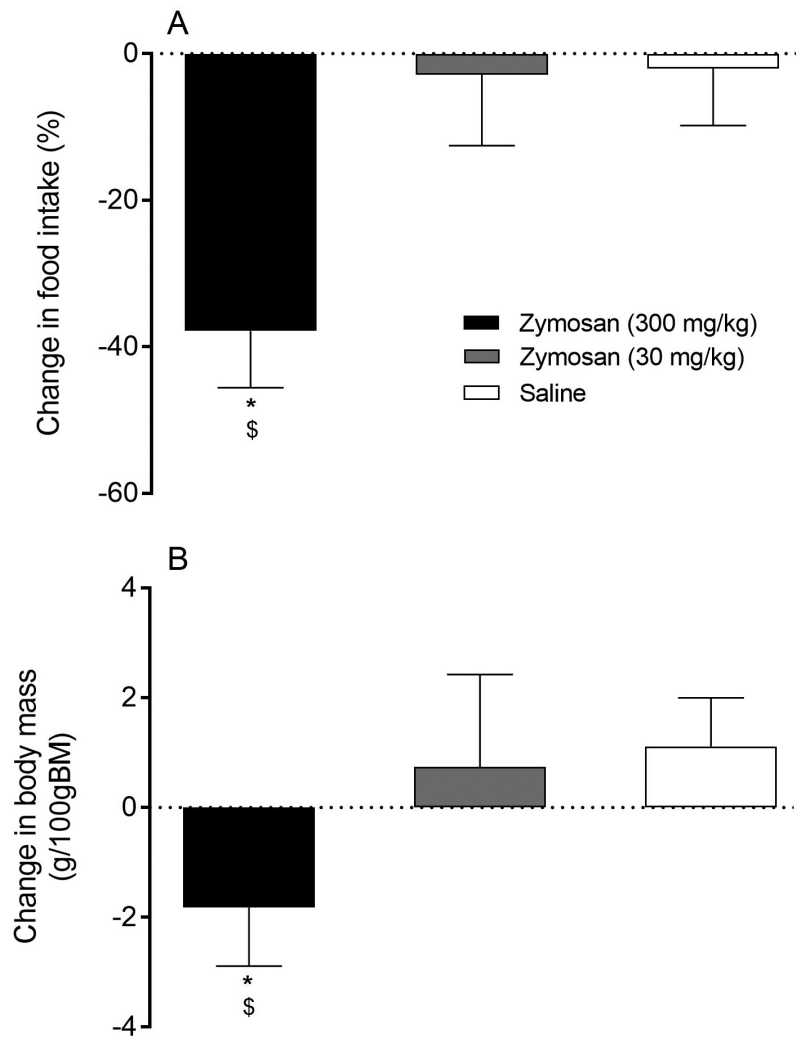

Fig. 3. Change in food intake (A) and body mass (B) (mean and standard deviation) of rats $24 \mathrm{~h}$ after receiving a subcutaneous injection of $300 \mathrm{mg} / \mathrm{kg}$ zymosan $(n=8), 30 \mathrm{mg} / \mathrm{kg}$ zymosan $(n=7)$, or saline $(n=7)$. For the $3 \mathrm{~d}$ before receiving an injection the average daily food consumption of the rats per $100 \mathrm{~g}$ of body mass was $7.5 \pm 0.3 \mathrm{~g}$. The average body mass of the rats before the injection was $282 \pm 22 \mathrm{~g}$. Food intake was calculated as grams of food consumed in $24 \mathrm{~h}$ per $100 \mathrm{~g}$ of body mass and expressed as a percentage change from the average daily food intake measured over $3 \mathrm{~d}$ before injection. Change in body mass $(\mathrm{g})$ was determined by subtracting the body mass measured $24 \mathrm{~h}$ after the injection from the body mass measured immediately before the injection and expressed as the change in body mass $(\mathrm{g})$ per $100 \mathrm{~g}$ of rat body mass. ${ }^{*}$ indicates differences between $300 \mathrm{mg} / \mathrm{kg}$ zymosan and saline ( $p<0.001$, Bonferroni). \$ indicates differences between 300 and $30 \mathrm{mg} / \mathrm{kg}$ zymosan $(p<0.01$, Bonferroni). A one sample $t$ test indicated that food intake decreased significantly from pre-injection values in rats receiving $300 \mathrm{mg} / \mathrm{kg}$ zymosan $(t=13.9$ and $p<0.0001)$, but not in rats receiving $30 \mathrm{mg} / \mathrm{kg}$ zymosan $(t=0.8$ and $p=0.46)$ or saline $(t=0.7$ and $p=0.52)$. A one sample $t$ test indicated a significant loss of body mass from pre-injection values in rats receiving $300 \mathrm{mg} / \mathrm{kg}$ zymosan $(t=4.8$ and $p=0.002)$, but not in rats receiving $30 \mathrm{mg} / \mathrm{kg}$ zymosan $(t=1.2$ and $p=0.29$ ); rats receiving saline significantly gained body mass $(t=3.3$ and $p=0.02)$.

$p<0.0001)$ ). Figure 4B shows that rats injected with zymosan had significantly elevated blood plasma levels of IL-6 at 2, 8, and $18 \mathrm{~h}$ after injection compared with rats injected with saline (main effects of time $\left(F_{(2,23)}=2.43, p=0.11\right)$, treatment $\left(F_{(1,23)}=189.70, p<0.0001\right)$, and interaction $\left(F_{(2,23)}=0.69\right.$, $p=0.51)$.

\section{Activation of NF-IL6, STAT-3, and COX-2 in the brain}

Figure 5 shows representative photomicrographs of immunohistochemical detection of NF-IL6 in the OVLT of rats injected subcutaneously with $300 \mathrm{mg} / \mathrm{kg}$ zymosan or saline. NF-IL6 immunoreactivity, which colocalized with the nuclear DAPI stain, appeared in this sensory circumventricular organ between 2 and $18 \mathrm{~h}$ after rats were injected with zymosan (Figs. 5C-5E). Rats injected with saline 

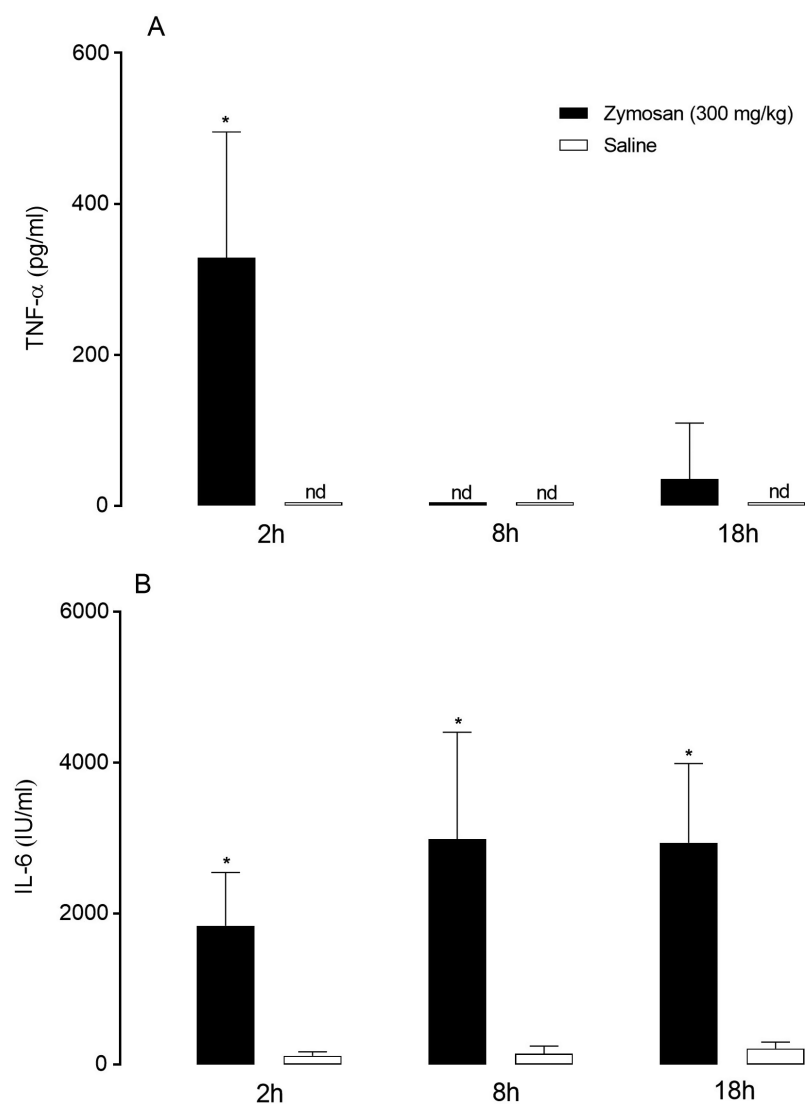

Fig. 4. Blood plasma levels of bioactive TNF- $\alpha$ (A) and IL-6 (B) at 2, 8, and $18 \mathrm{~h}$ after receiving a subcutaneous injection of $300 \mathrm{mg} / \mathrm{kg}$ zymosan or saline. Sample size per intervention group per time point was 4-6 rats. * indicates significant differences between $300 \mathrm{mg} / \mathrm{kg}$ zymosan and saline ( $p<0.0001$, Bonferroni); nd, not detectable.

did not show nuclear NF-IL6 immunoreactivity in the OVLT at any time points (Fig. 5B). The nuclear NF-IL6 signals were closely associated with blood vessels in the OVLT as shown by an additional colocalization with von Willebrand factor (vWF).

Figure 6 shows representative high magnification photomicrographs of immunohistochemical detection of STAT-3 activation in the OVLT of rats injected with $300 \mathrm{mg} / \mathrm{kg}$ zymosan or saline. STAT-3 immunoreactivity, which colocalized with the nuclear DAPI stain, appeared in this sensory circumventricular organ between 2 and $18 \mathrm{~h}$ after rats were injected with zymosan (Figs. 6B-6D). Rats injected with saline did not show nuclear STAT-3 immunoreactivity at any of the time points (Fig. 6A). The nuclear STAT-3 signals were closely associated with blood vessels in the OVLT, as shown by an additional colocalization with vWF.

Figure 7 shows representative high magnification photomicrographs of immunohistochemical detection of the enzyme COX-2 in the OVLT of rats injected with $300 \mathrm{mg} / \mathrm{kg}$ zymosan or saline. Typical perinuclear COX-2 immunoreactivity was detected in this sensory circumventricular organ between 2 and $18 \mathrm{~h}$ after rats were injected with zymosan (Figs. 7B-7D). The perinuclear COX-2 signals colocalized with blood vessels in the OVLT as shown by an additional colocalization with vWF (Figs. 7B and 7D). Perinuclear COX-2 immunoreactivity was also detected in the walls of large vessels 

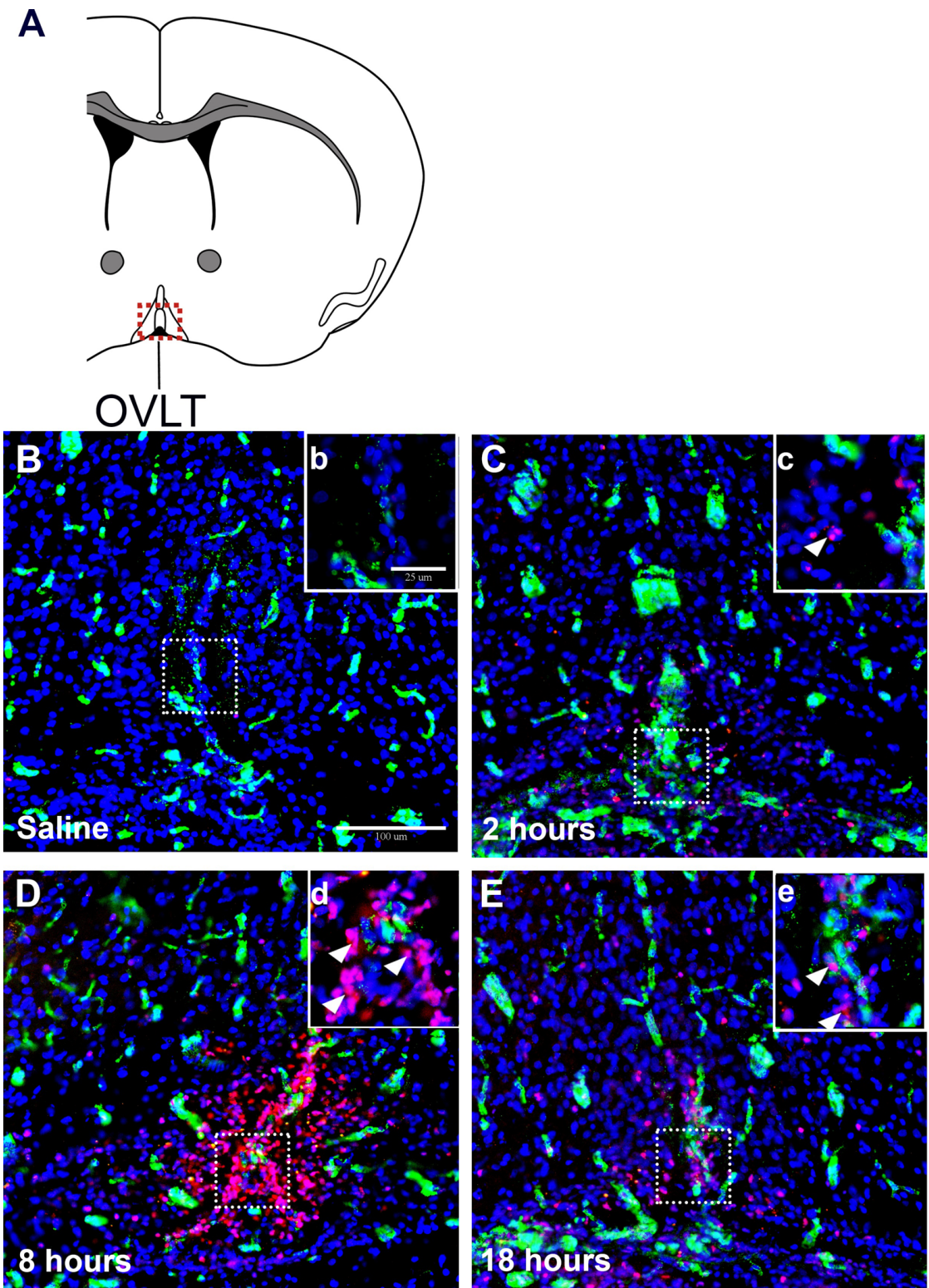

Fig. 5. Nuclear NF-IL6 (red) immunoreactivity in the OVLT at 2, 8, and $18 \mathrm{~h}$ after subcutaneous injection of $300 \mathrm{mg} / \mathrm{kg}$ zymosan or saline. (A) Schematic overview of the rat brain showing the position of the OVLT. The white arrowheads show the colocalization of the red NF-IL6 signals with the nuclear DAPI stain (blue) that indicates the nuclear localization of the signals, which appeared at 2, 8, and $18 \mathrm{~h}(\mathrm{C}-\mathrm{E})$ after injection with zymosan. Subcutaneous injection of rats with saline was not associated with nuclear NF-IL6 immunoreactivity (B). Endothelial cells of blood vessels were stained with von Willebrand factor (green). NF-IL6 staining (red) was associated with the endothelium of blood vessels as shown by colocalization with von Willebrand factor (green). The locations of areas used for high magnification are indicated by a dashed square in the overviews. Scale bar in: (B) represents $100 \mu \mathrm{m}$ and applies to $20 \times$ magnification micrographs (B-E); (b) represents $25 \mu \mathrm{m}$ and applies to $40 \times$ magnification inserts (b-e).

with large lumens in the subarachnoid space, lateral to the optic chiasm (images not shown). No perinuclear COX-2 signals were observed in blood vessels in the OVLT at any of the time points in rats injected with saline (Fig. 7A). 

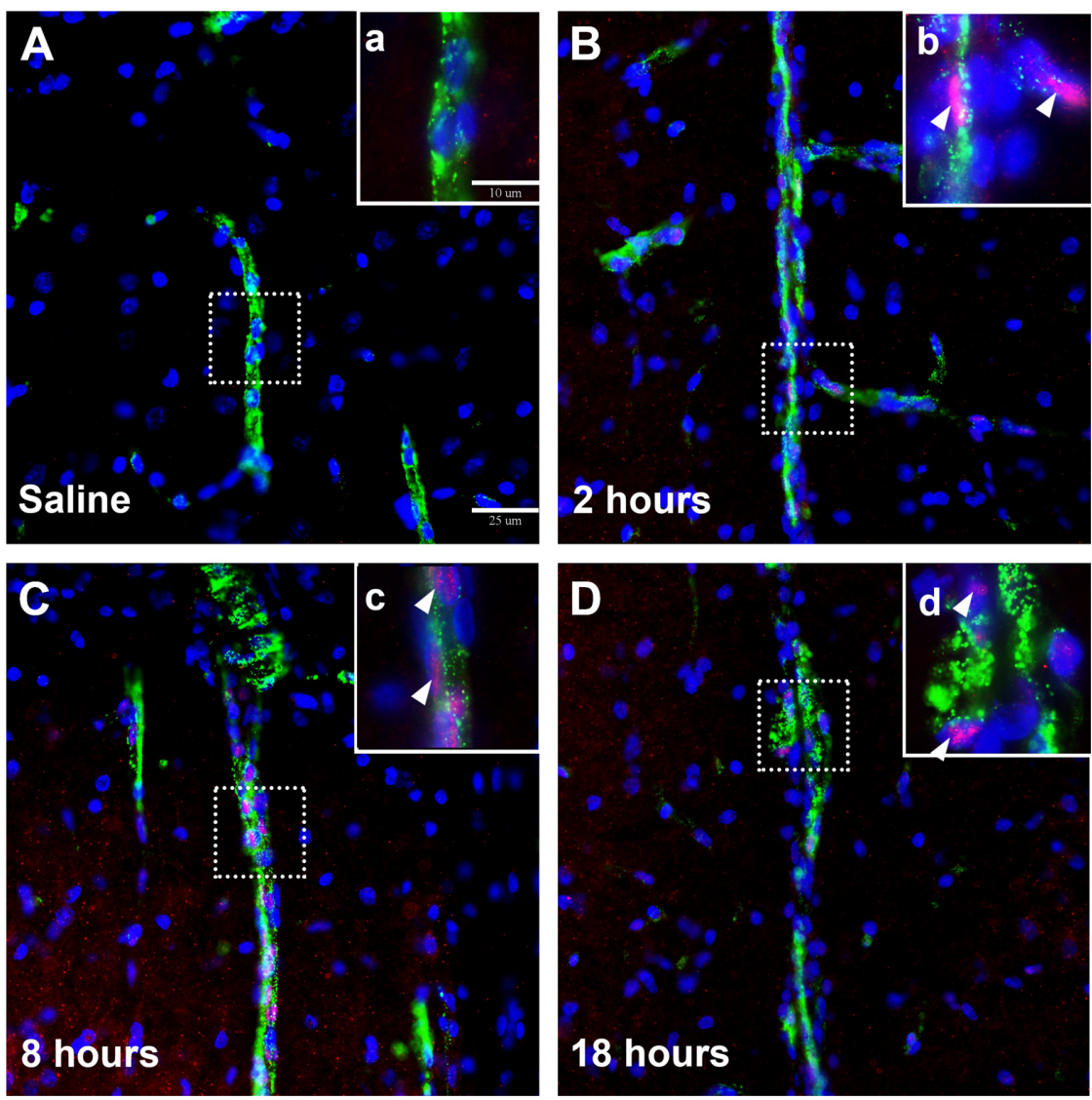

Fig. 6. Nuclear STAT-3 (red) immunoreactivity in the OVLT at 2, 8, and $18 \mathrm{~h}$ after subcutaneous injection of either $300 \mathrm{mg} / \mathrm{kg}$ zymosan or saline. The white arrowheads show the colocalization of red STAT-3 signals with the nuclear DAPI stain (blue) that indicates the nuclear localization of the signals, which appeared at 2,8 , and $18 \mathrm{~h}(\mathrm{~B}-\mathrm{D})$ after injection with zymosan. Subcutaneous injection of rats with saline was not associated with nuclear translocation of STAT-3 (A). Endothelial cells of blood vessels were stained with von Willebrand factor (green). STAT-3 staining (red) was associated with the endothelium of blood vessels as shown by colocalization with von Willebrand factor (green). The locations of areas used for high magnification are indicated by a dashed square in the overviews. Scale bar in: $(A)=25 \mu \mathrm{m}$ and applies to all micrographs $(\mathrm{A}-\mathrm{D})$ which were taken at $40 \times$ magnification; $(a)=10 \mu \mathrm{m}$ and applies to all inserts $(\mathrm{a}-\mathrm{d})$ which were taken at $100 \times$ magnification.

\section{Relative mRNA expression of inflammatory mediators in the hypothalamus}

Figure 8 shows the increase in hypothalamic mRNA expression of pro-inflammatory target genes and regulatory proteins of transcription factors following injection of $300 \mathrm{mg} / \mathrm{kg}$ zymosan or saline in rats. Figures $8 \mathrm{~A}$ and $8 \mathrm{~B}$ shows that rats injected with zymosan had significantly greater mRNA expression of NF-IL6 and I $\mathrm{B} \alpha$ (the negative regulator of NF- $\kappa \mathrm{B}$ ) in the hypothalamus at 8 and $18 \mathrm{~h}$ compared with rats injected with saline (NF-IL6: main effects of time $\left(F_{(2,23)}=3.54, p=0.05\right)$, treatment $\left(F_{(1,23)}=27.18\right.$,

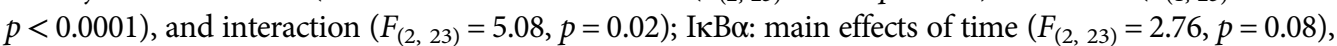
treatment $\left(F_{(1,23)}=17.12, p=0.0004\right)$, and interaction $\left.\left(F_{(2,23)}=0.66, p=0.52\right)\right)$.

Figure $8 \mathrm{C}$ shows that rats injected with zymosan had significantly greater mRNA expression of SOCS-3 in the hypothalamus at 2,8 , and $18 \mathrm{~h}$ compared with rats injected with saline (main effects of time $\left(F_{(2,23)}=4.27, p=0.03\right)$, treatment $\left(F_{(1,23)}=147.20, p<0.0001\right)$, and interaction $\left(F_{(2,23)}=4.42\right.$, $p=0.02)$ ). 

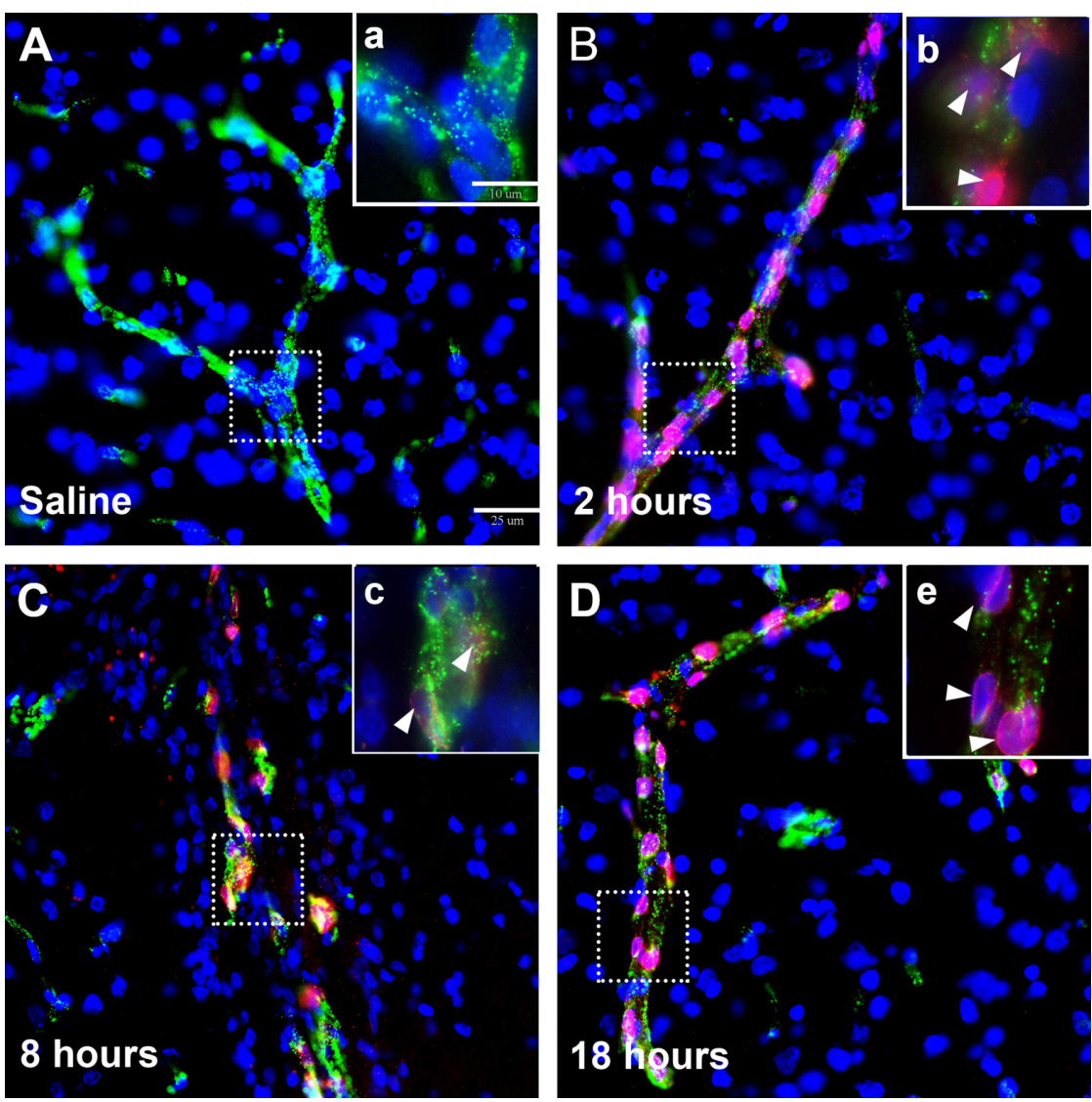

Fig. 7. Perinuclear COX-2 immunoreactivity (red) in the OVLT at 2, 8 , and $18 \mathrm{~h}$ after subcutaneous injection of either $300 \mathrm{mg} / \mathrm{kg}$ zymosan or saline. The white arrowheads show the colocalization of the red COX-2 signals with the nuclear DAPI stain (blue) that indicates the perinuclear localization of the signals, which appeared at 2, 8 , and $18 \mathrm{~h}(\mathrm{~B}-\mathrm{D})$ after injection with zymosan. Subcutaneous injection of rats with saline was not associated with COX-2 immunoreactivity (A). Endothelial cells of blood vessels were stained with von Willebrand factor (green). COX-2 staining (red) was associated with the endothelium of blood vessels as shown by colocalization with von Willebrand factor (green). The locations of areas used for high magnification are indicated by a dashed square in the overviews. Scale bar in: $(A)=25 \mu \mathrm{m}$ and applies to all micrographs (A-D) which were taken at $40 \times$ magnification; (a) $=10 \mu \mathrm{m}$ and applies to all inserts $(\mathrm{a}-\mathrm{d})$ which were taken at $100 \times$ magnification.

Figures $8 \mathrm{D}-8 \mathrm{~F}$ show that rats injected with zymosan had significantly greater hypothalamic TNF- $\alpha$ mRNA expression at 8 and $18 \mathrm{~h}$, IL- 6 mRNA expression at $8 \mathrm{~h}$ and IL- $1 \beta$ mRNA expression at 2,8 , and $18 \mathrm{~h}$ compared with rats injected with saline (TNF- $\alpha$ : main effects of time $\left(F_{(2,23)}=12.47\right.$, $p=0.0002)$, treatment $\left(F_{(1,23)}=31.38, p<0.0001\right)$, and interaction $\left(F_{(2,23)}=5.56, p=0.01\right)$; IL-6: main effects of time $\left(F_{(2,23)}=0.69, p=0.51\right)$, treatment $\left(F_{(1,23)}=8.18, p=0.009\right)$, and interaction $\left(F_{(2,23)}=1.34, p=0.28\right)$; IL-1 $\beta$ : main effects of time $\left(F_{(2,23)}=21.68, p<0.0001\right)$, treatment $\left(F_{(1,23)}=153.70, p<0.0001\right)$, and interaction $\left.\left(F_{(2,23)}=15.39, p<0.0001\right)\right)$.

Figures $8 \mathrm{G}$ and $8 \mathrm{H}$ show that rats injected with zymosan had significantly greater hypothalamic COX-2 mRNA expression at 2, 8 , and $18 \mathrm{~h}$ and mPGES mRNA expression at 8 and $18 \mathrm{~h}$ compared with rats injected with saline (COX-2: main effects of time $\left(F_{(2,23)}=2.33, p=0.12\right)$, treatment $\left(F_{(1,23)}=42.29\right.$, $p<0.0001)$, and interaction $\left(F_{(2,23)}=1.80, p=0.19\right)$; mPGES: (main effects of time $\left(F_{(2,23)}=57.04\right.$, $p<0.0001)$, treatment $\left(F_{(1,23)}=265.50, p<0.0001\right)$, and interaction $\left.\left(F_{(2,23)}=57.22, p<0.0001\right)\right)$. 

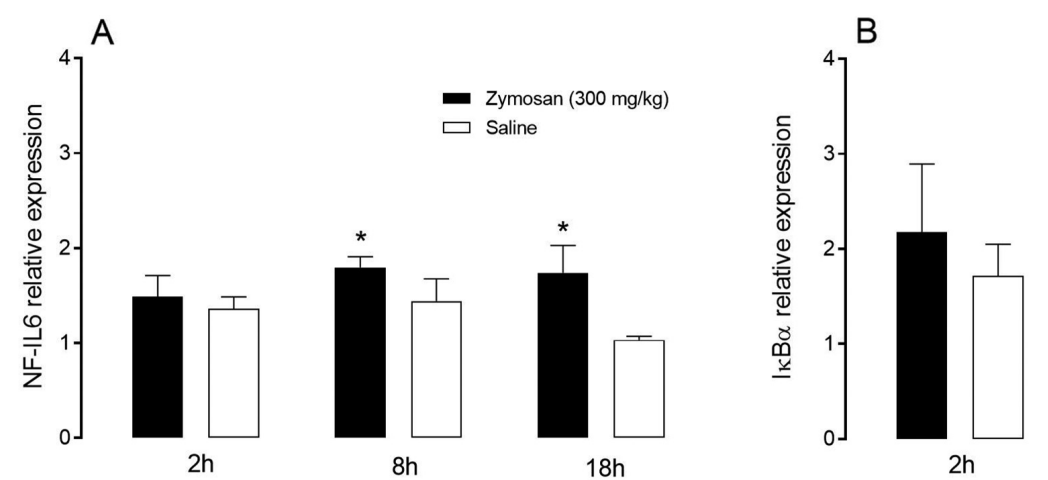
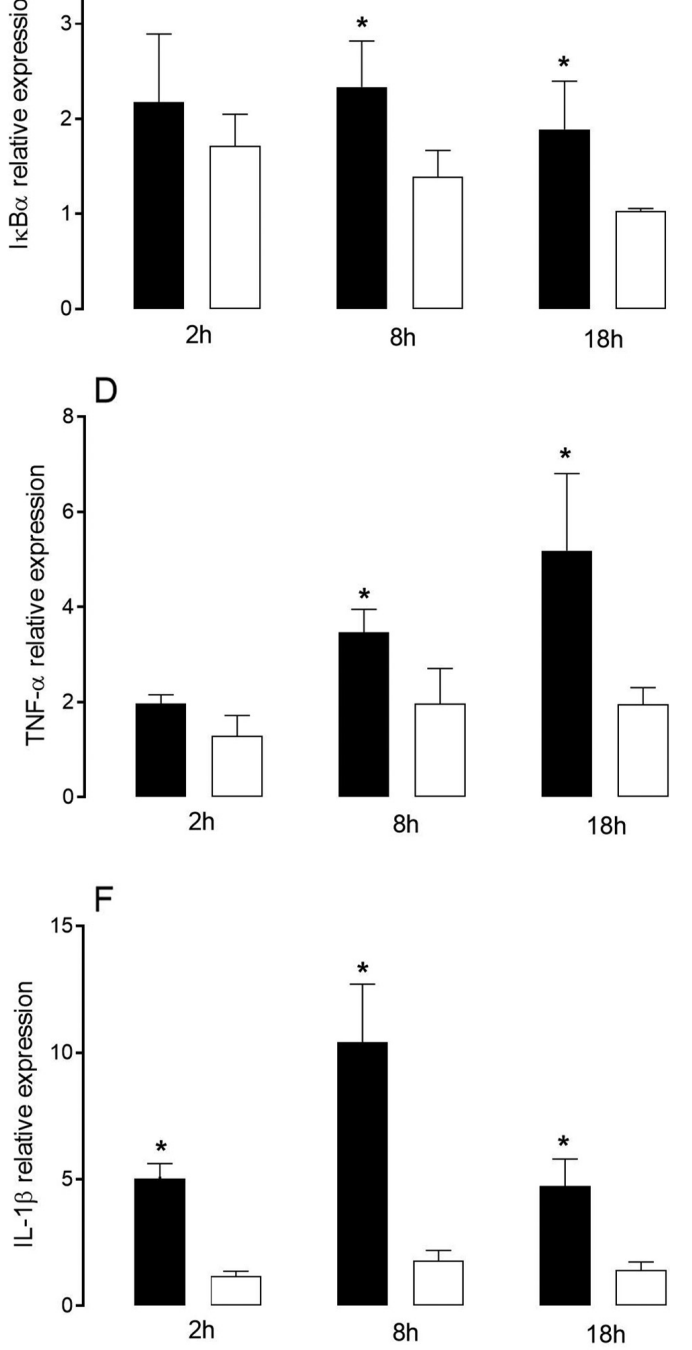

$8 \mathrm{~h}$
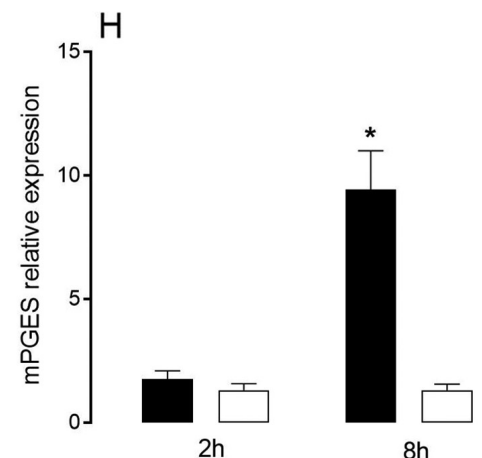

$8 \mathrm{~h}$
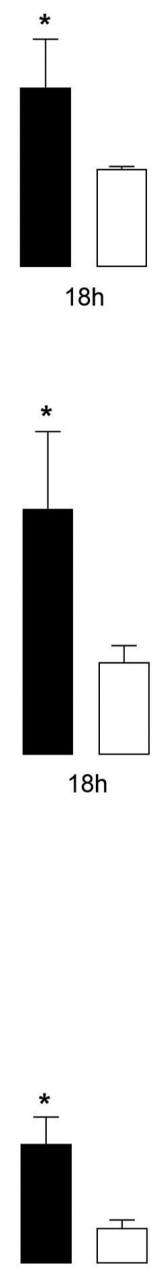

$18 \mathrm{~h}$

$18 \mathrm{~h}$

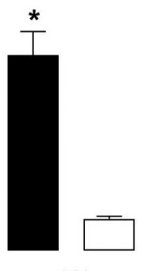

$18 \mathrm{~h}$

Fig. 8. Relative mRNA expression (mean and standard deviation) of transcription factors or markers of their activation (A-C), pro-inflammatory cytokines (D-F), and rate-limiting enzymes for $\mathrm{PGE}_{2}$ synthesis ( $\mathrm{G}$ and $\mathrm{H}$ ) in the rat hypothalamus at 2, 8, and $18 \mathrm{~h}$ after subcutaneous injection of either $300 \mathrm{mg} / \mathrm{kg}$ zymosan or saline. Sample size per intervention group per time point was $4-6$ rats. ${ }^{*}$ indicates significant differences between $300 \mathrm{mg} / \mathrm{kg}$ zymosan and saline $(p<0.05$, Bonferroni). 


\section{Discussion}

We have shown that subcutaneous administration of $300 \mathrm{mg} / \mathrm{kg}$ zymosan induces fever, lethargy, anorexia, and growth stunting for $24 \mathrm{~h}$ (Figs. 1-3). For the first time, we identify that accompanying this suite of sickness responses induced by zymosan is enhanced brain mRNA and protein expression of key inflammatory transcription factors (NF-IL6 and STAT-3) and regulators (I $\mathrm{B} \alpha$ and SOCS-3) (Figs. 5, 6, and 8). In line with the increase in inflammatory transcription factors, we noted an increase in the concentration of circulating TNF- $\alpha$ and IL-6 (Fig. 4) and hypothalamic mRNA expression of TNF- $\alpha$, IL-1 $\beta$, and IL- 6 and rate-limiting enzymes for prostaglandin synthesis (COX-2 and mPGES) (Fig. 8). Furthermore, the nuclear immunoreactivity for NF-IL6 and STAT-3 and perinuclear COX-2 immunoreactivity, which we noted in the brain, was associated with blood vessels in the OVLT of rats injected with zymosan (Figs. 5-7).

From the results of our own study and those of others, it is clear that the characteristics of the sickness response to zymosan administration are dependent on the dose of zymosan injected. In our study, subcutaneously injecting $300 \mathrm{mg} / \mathrm{kg}$ of zymosan induced a fever of $1-2{ }^{\circ} \mathrm{C}$ for $24 \mathrm{~h}$, whereas subcutaneously injecting $30 \mathrm{mg} / \mathrm{kg}$ of zymosan induced a fever of $0.3-0.5^{\circ} \mathrm{C}$ for $18 \mathrm{~h}$. Others have shown that intraperitoneal injection of lower doses $(1-10 \mathrm{mg} / \mathrm{kg}$ ) of zymosan induced short-lived (about $4 \mathrm{~h}$ ) fevers of $1-1.5^{\circ} \mathrm{C}$ in rats (Hubschle et al. 2007; Bastos-Pereira et al. 2014) and that intraperitoneal injection of higher doses $(800-1000 \mathrm{mg} / \mathrm{kg})$ induced hypothermia, shock, multiple organ failure, and mortality (as reviewed in Volman et al. (2005)). One of the prominent differences noted in the fever profile between our study where zymosan $(30$ and $300 \mathrm{mg} / \mathrm{kg}$ ) was administered subcutaneously and previous studies where zymosan $(3-10 \mathrm{mg} / \mathrm{kg}$ ) was administered intraperitoneally is a longer plateau phase of 7-10 h (Hubschle et al. 2007; Bastos-Pereira et al. 2014). Moreover, the anorexia, lethargy, and loss of body mass we noted with subcutaneous administration of $300 \mathrm{mg} / \mathrm{kg}$ zymosan was more pronounced than that noted with intraperitoneal administration of $10 \mathrm{mg} / \mathrm{kg}$ zymosan (Hubschle et al. 2007). Overall, an important finding of our study is that subcutaneous administration of $300 \mathrm{mg} / \mathrm{kg}$ zymosan in rats can produce sickness responses of a similar magnitude to that noted with subcutaneous administration of Brewer's yeast in rats (4 and $2 \mathrm{~g} / \mathrm{kg}$ ) (Dangarembizi et al. 2018). Based on the findings of our current study, subcutaneous administration of $300 \mathrm{mg} / \mathrm{kg}$ zymosan is, thus, a viable alternative pyrogen to subcutaneous administration of Brewer's yeast in studies wanting to investigate the long-term effectiveness of antipyretic and anti-inflammatory drugs at attenuating sickness responses.

Establishing efficient protocols for antipyretic and anti-inflammatory drug screening not only requires characterization of the sickness profile induced by zymosan administration but also the inflammatory profile. Simultaneously describing the sickness responses and the inflammatory mediators allows for not only screening drugs but also determining the mechanism of action of effective drugs. Our findings show that subcutaneous injection of $300 \mathrm{mg} / \mathrm{kg}$ of zymosan increases the concentration of circulating TNF- $\alpha$ and IL-6 (Fig. 4) and increases hypothalamic mRNA expression of TNF- $\alpha$, IL- $1 \beta$, and IL-6 (Fig. 8). Circulating levels of TNF- $\alpha$ were elevated during the early phase of fever $(2 \mathrm{~h})$ and circulating levels of IL- 6 were elevated during the early phase $(2 \mathrm{~h})$ and plateau phase ( 8 and $18 \mathrm{~h}$ ) of fever (Figs. 1 and 4 ). These findings indicate that both circulating TNF- $\alpha$ and IL-6 may be involved in the early development of zymosan-induced fever, whereas circulating IL-6 appears to play a more prominent role in the maintenance of zymosan-induced fever. Others have also noted increased levels of TNF- $\alpha$ in serum and peritoneal lavage fluid of mice $1-3 \mathrm{~h}$ following intraperitoneal administration of zymosan $(25$ and $80 \mathrm{mg} / \mathrm{kg}$ ) (von Asmuth et al. 1990; Fantuzzi et al. 1997). Increased levels of IL-6 in serum were noted $3 \mathrm{~h}$ following intraperitoneal administration of zymosan (3 mg/kg) in rats (Bastos-Pereira et al. 2014). The increase in hypothalamic TNF- $\alpha$ and IL- 6 mRNA expression occurred during the plateau phase of the fever, 8 and $18 \mathrm{~h}$ after zymosan administration $(300 \mathrm{mg} / \mathrm{kg})$. In line with the increased hypothalamic mRNA expression of TNF- $\alpha$ 
and IL-6, we also noted an increase in hypothalamic mRNA expression of IL-1 $\beta$ during the early phase $(2 \mathrm{~h})$ and plateau phase ( 8 and $18 \mathrm{~h}$ ) of zymosan-induced fever. Using intra-cerebroventricular injection of antibodies to TNF- $\alpha$, IL- 6 and IL-1 receptor antagonist, others have shown that the inhibition of brain TNF- $\alpha$, IL- 6 , and IL- $1 \beta$ activity attenuates the magnitude and duration of zymosan-induced fever (Bastos-Pereira et al. 2014). Our study adds to these findings by identifying the hypothalamus as a potential source for centrally acting cytokines during zymosan-induced inflammation. Thus, although circulating TNF- $\alpha$ and IL- 6 may play a role in initiating the fever, hypothalamic TNF- $\alpha$, IL- 6 , and IL- $1 \beta$ likely play a role in the maintenance of zymosan-induced fever. Overall, the role of peripheral and hypothalamic pro-inflammatory cytokines released with subcutaneous zymosan administration is similar to that noted with subcutaneous administration of Brewer's yeast ( 2 and $4 \mathrm{~g} / \mathrm{kg}$ ). There are however, some differences in terms of the magnitude and temporal responses of individual cytokines with subcutaneous administration of Brewer's yeast inducing responses of a greater magnitude and longer duration than those noted with subcutaneous administration of zymosan (Dangarembizi et al. 2018).

In addition to an increase in hypothalamic mRNA expression of pro-inflammatory cytokines, we noted an increase in hypothalamic mRNA expression of the enzymes required for prostaglandin (PG)E $E_{2}$ synthesis, namely COX-2 and mPGES (Saper and Breder 1994; Rummel et al. 2011; Wilhelms et al. 2014; Vasilache et al. 2015). Accompanying the fever induced by intraperitoneal administration of zymosan $(3 \mathrm{mg} / \mathrm{kg})$ is an increase in cerebrospinal fluid (CSF) levels of $\mathrm{PGE}_{2}$ (Bastos-Pereira et al. 2017). The finding that a non-selective COX-inhibitor (indomethacin) and a COX-2 selective inhibitor (celecoxib) can attenuate zymosan-induced fever and the increase in CSF levels of $\mathrm{PGE}_{2}$ supports the notion that brain-based $\mathrm{PGE}_{2}$ produced via COX-2 is an important mediator of zymosan-induced fever (Kanashiro et al. 2009; Bastos-Pereira et al. 2017). Our study highlights that the source of COX-2 required for brain-based $\mathrm{PGE}_{2}$ synthesis is likely to include the hypothalamus as well as endothelial cells of blood vessels in the OVLT (Fig. 7). These finding are in line with our previous observations with subcutaneous administration of Brewer's yeast, with the exception that COX-2 mRNA and protein expression seems to appear earlier in the hypothalamus and OVLT following zymosan administration (Dangarembizi et al. 2018).

The synthesis of $\mathrm{PGE}_{2}$ and pro-inflammatory cytokines requires activation of inflammatory transcription factors, such as NF-IL6, STAT-3, and NF- $\mathrm{kB}$ (for review see Rummel (2016)). Using immunohistochemical staining and real-time PCR we examined the mRNA expression, activation, and translocation of the transcription factors in the brains of rats injected subcutaneously with zymosan $(300 \mathrm{mg} / \mathrm{kg}$ ). Our main areas of interest in the brain where the hypothalamus, OVLT, and endothelial cells, as others have shown that stimulating rat primary neuroglial cultures, obtained from the OVLT and hypothalamic median preoptic nucleus, with zymosan induces the synthesis of pro-inflammatory cytokines (Bastos-Pereira et al. 2014). The pro-inflammatory cytokine response induced by zymosan appears to require TLR2 and TLR6 signalling (Ozinsky et al. 2000) and the expression of TLR2 and TLR6 occurs on cerebral endothelial cells and microglia (Olson and Miller 2004; Nagyöszi et al. 2010).

In our study, activation and nuclear translocation of NF-IL6 was closely associated with endothelial cells of blood vessels in the OVLT and occurred primarily around the plateau phase $(8 \mathrm{~h})$ of zymosan-induced fever in rats (Fig. 5). The late induction of NF-IL6 is similar to the induction pattern reported for Brewer's yeast and indicates that NF-IL6 may be more active during the latter rather than the earlier phase of the zymosan-induced sickness response (Dangarembizi et al. 2018). Overall, the activation of NF-IL6 in the OVLT by zymosan and Brewer's yeast carries important functional significance, as this sensory circumventricular organ lies close to and has numerous neural connections with the febrigenic zones of the hypothalamus (Blatteis 1992). Collectively the results obtained with administration of zymosan and Brewer's yeast indicate that endothelial cells, microglia, 
astrocytes and neurons within the OVLT may therefore be an important link in inflammatory signalling between the periphery and the brain during fungal infections.

It has been mooted that there is transcriptional synergism between NF-IL6 and NF- $\mathrm{KB}$ and that the two transcription factors co-regulate gene expression of inflammatory cytokines (Matsusaka et al. 1993; Santos et al. 2011). Previous studies have shown that coexpression of TLR2 and TLR6 strongly activate NF-kB (Ozinsky et al. 2000). Although we did not perform immunohistochemical staining of $\mathrm{NF}-\mathrm{\kappa B}$ in this study, we did measure the expression of its regulatory inhibitory molecule IkB $\alpha$, which usually matches the activation pattern of NF- $\mathrm{KB}$ (Quan et al. 1997). We noted enhanced hypothalamic mRNA expression of $\mathrm{IkB} \alpha$ during the plateau phase $(8-18 \mathrm{~h})$ of zymosan-induced fever in rats. Overall, our findings confirm observations obtained with cell cultures indicating that both the NF-IL6 and NF- $\mathrm{KB}$ pathways may mediate the zymosan-induced inflammatory response (Santos et al. 2011).

In addition to showing the activation of NF-IL6 and NF- $\mathrm{KB}$ in the brain, we observed activation of STAT-3, associated with blood vessels in the OVLT, during the early phase $(2 \mathrm{~h})$ and plateau phase ( 8 and $18 \mathrm{~h}$ ) of zymosan-induced fever (Fig. 6). Moreover, a pronounced increase in the expression of the STAT-3 regulator, SOCS-3, occurred in the hypothalamus during the course of the zymosaninduced fever (Fig. 8). These findings suggest that in addition to stimulating NF- $\kappa B$ and NF-IL6 signalling pathways, zymosan may induce neuroinflammation through activation of the JAK/STAT signalling pathway. Previous studies have shown that STAT-3 and SOCS-3 were increased in synovial tissue obtained from mice that received an intraarticular injection of zymosan (de Hooge

et al. 2004). Overall, we noted a similar pattern of induction of brain mRNA and protein expression of key inflammatory transcription factors (NF-IL6 and STAT-3) and regulators (IאB $\alpha$ and SOCS3) with subcutaneous administration of zymosan and Brewer's yeast in rats (Dangarembizi et al. 2018).

\section{Conclusion}

In conclusion, the results obtained from our study show that subcutaneous administration of zymosan induces a long-lasting $(24 \mathrm{~h})$ fever that is accompanied by lethargy, anorexia, and a decrease in body mass. Accompanying the sickness responses induced by zymosan are an increase in circulating cytokines (IL-6 and TNF- $\alpha$ ), activation of inflammatory transcription factors (NF-IL6, NF- $\kappa B$, and STAT-3), and an upregulation of their target genes (central cytokines and inducible $\mathrm{PGE}_{2}$ synthesizing enzymes) in the brain. These results identify the suitability of using zymosan as an alternative pyrogen for screening antipyretic and anti-inflammatory drugs in rats.

\section{Acknowledgements}

We are grateful to the Doreen Marks, Jolanta Murgott, Nyasha Mukonowenzou, and Mariam Sabbar for their assistance with experimental procedures and the staff at the Central Animal Services for assistance with animal handling and welfare. This work was supported by funding received from an Alexander von Humboldt Foundation Group Linkage Program, National Research Foundation of South Africa (grant number: 111718), and the Faculty of Health Sciences Research Committee, University of the Witwatersrand.

\section{Author contributions}

$\mathrm{RD}, \mathrm{CDR}$, JR, KHE, and LMH conceived and designed the study. RD, CDR, JR, KHE, and LMH performed the experiments/collected the data. RD, CDR, JR, KHE, and LMH analyzed and interpreted the data. RD, CDR, JR, KHE, and LMH contributed resources. RD, CDR, JR, KHE, MTM, and LMH drafted or revised the manuscript. 


\section{Competing interests}

The authors have declared that no competing interests exist.

\section{Data availability statement}

All relevant data are within the paper.

\section{References}

Aarden LA, De Groot ER, Schaap OL, and Lansdorp PM. 1987. Production of hybridoma growth factor by human monocytes. European Journal of Immunology, 17: 1411-1416. PMID: 3500054 DOI: $10.1002 /$ eji.1830171004

Bastos-Pereira AL, Fraga D, Ott D, Simm B, Murgott J, Roth J, et al. 2014. Involvement of brain cytokines in zymosan-induced febrile response. Journal of Applied Physiology, 116: 1220-1229. PMID: 24651990 DOI: 10.1152/japplphysiol.01278.2013

Bastos-Pereira AL, Fraga D, Dreifuss AA, and Zampronio AR. 2017. Central mediators of the zymosan-induced febrile response. Journal of Basic and Clinical Physiology and Pharmacology, 28: 555-562. PMID: 28981444 DOI: 10.1515/jbcpp-2017-0061

Baumans V. 2004. Use of animals in experimental research: an ethical dilemma? Gene Therapy, 11: S64-S66. PMID: 15454959 DOI: 10.1038/sj.gt.3302371

Blatteis CM. 1992. Role of the OVLT in the febrile response to circulating pyrogens. Progress in Brain Research, 91: 409-412. PMID: 1384084 DOI: 10.1016/S0079-6123(08)62360-2

Damm J, Luheshi GN, Gerstberger R, Roth J, and Rummel C. 2011. Spatiotemporal nuclear factor interleukin-6 expression in the rat brain during lipopolysaccharide-induced fever is linked to sustained hypothalamic inflammatory target gene induction. The Journal of Comparative Neurology, 519: 480-505. PMID: 21192080 DOI: 10.1002/cne.22529

Dangarembizi R, Erlwanger KH, Rummel C, Roth J, Madziva MT, and Harden LM. 2018. Brewer's yeast is a potent inducer of fever, sickness behavior and inflammation within the brain. Brain, Behavior, and Immunity, 68: 211-223. PMID: 29074357 DOI: 10.1016/j.bbi.2017.10.019

de Hooge ASK, van de Loo FAJ, Koenders MI, Bennink MB, Arntz OJ, Kolbe T, et al. 2004. Local activation of STAT-1 and STAT-3 in the inflamed synovium during zymosan-induced arthritis: exacerbation of joint inflammation in STAT-1 gene-knockout mice. Arthritis \& Rheumatology, 50: 2014-2023. PMID: 15188379 DOI: 10.1002/art.20302

Eskilsson A, Mirrasekhian E, Dufour S, Schwaninger M, Engblom D, and Blomqvist A. 2014. Immuneinduced fever is mediated by IL- 6 receptors on brain endothelial cells coupled to STAT3-dependent induction of brain endothelial prostaglandin synthesis. The Journal of Neuroscience, 34: 15957-15961. PMID: 25429137 DOI: 10.1523/JNEUROSCI.3520-14.2014

Espevik T, and Nissen-Meyer J. 1986. A highly sensitive cell line, WEHI 164 clone 13, for measuring cytotoxic factor/tumor necrosis factor from human monocytes. Journal of Immunological Methods, 95: 99-105. PMID: 3782828 DOI: 10.1016/0022-1759(86)90322-4

Fantuzzi G, Sacco S, Ghezzi P, and Dinarello CA. 1997. Physiological and cytokine responses in IL-1 beta-deficient mice after zymosan-induced inflammation. American Journal of 
Physiology—Regulatory, Integrative and Comparative Physiology, 273: R400-R406. PMID: 9249578 DOI: 10.1152/ajpregu.1997.273.1.R400

Fuchs F, Damm J, Gerstberger R, Roth J, and Rummel C. 2013. Activation of the inflammatory transcription factor nuclear factor interleukin-6 during inflammatory and psychological stress in the brain. Journal of Neuroinflammation, 10: 905. PMID: 24279606 DOI: 10.1186/1742-2094-10-140

Gegout P, Gillet P, Chevrier D, Guingamp C, Terlain B, and Netter P. 1994. Characterization of zymosan-induced arthritis in the rat: effects on joint inflammation and cartilage metabolism. Life Sciences, 55: PL321-PL326. PMID: 7934634 DOI: 10.1016/0024-3205(94)00771-3

Hopwood N, Maswanganyi T, and Harden LM. 2009. Comparison of anorexia, lethargy, and fever induced by bacterial and viral mimetics in rats. Canadian Journal of Physiology and Pharmacology, 87: 211-220. PMID: 19295662 DOI: 10.1139/Y09-003

Hubschle T, Rafalzik S, Gerstberger R, and Roth J. 2007. Induction of fever and sickness behavior in telemetrically monitored rats during systemic inflammation induced by zymosan. Journal of Animal and Veterinary Advances, 6: 569-575.

Kanashiro A, Pessini AC, Machado RR, Malvar DDC, Aguiar FA, Soares DM, et al. 2009. Characterization and pharmacological evaluation of febrile response on zymosan-induced arthritis in rats. American Journal of Physiology-Regulatory, Integrative and Comparative Physiology, 296: R1631-R1640. PMID: 19244587 DOI: 10.1152/ajpregu.90527.2008

Lima JBM, Veloso CC, Vilela FC, and Giusti-Paiva A. 2017. Prostaglandins mediate zymosan-induced sickness behavior in mice. The Journal of Physiological Sciences, 67: 673-679. PMID: 27699583 DOI: $10.1007 /$ s12576-016-0494-8

Matsusaka T, Fujikawa K, Nishio Y, Mukaida N, Matsushima K, Kishimoto T, et al. 1993. Transcription factors NF-IL6 and NF-kappa B synergistically activate transcription of the inflammatory cytokines, interleukin 6 and interleukin 8. Proceedings of the National Academy of Sciences of the USA, 90: 10193-10197. PMID: 8234276 DOI: 10.1073/pnas.90.21.10193

Nagyőszi P, Wilhelm I, Farkas AE, Fazakas C, Dung NTK, Haskó J, et al. 2010. Expression and regulation of toll-like receptors in cerebral endothelial cells. Neurochemistry International, 57: 556-564. PMID: 20637248 DOI: 10.1016/j.neuint.2010.07.002

Naoi K, Kogure S, Saito M, Hamazaki T, and Watanabe S. 2006. Differential effects of selective cyclooxygenase (COX)-1 and COX-2 inhibitors on anorexic response and prostaglandin generation in various tissues induced by zymosan. Biological and Pharmaceutical Bulletin, 29: 1319-1324. PMID: 16819161 DOI: 10.1248/bpb.29.1319

National Research Council. 2010. Guide for the care and use of laboratory animals. National Academies Press, Washington, D.C.

Olson JK, and Miller SD. 2004. Microglia initiate central nervous system innate and adaptive immune responses through multiple TLRs. The Journal of Immunology, 173: 3916-3924. PMID: 15356140 DOI: 10.4049/jimmunol.173.6.3916

Ott D, Murgott J, Rafalzik S, Wuchert F, Schmalenbeck B, Roth J, et al. 2010. Neurons and glial cells of the rat organum vasculosum laminae terminalis directly respond to lipopolysaccharide and pyrogenic cytokines. Brain Research, 1363: 93-106. PMID: 20883673 DOI: 10.1016/j.brainres.2010.09.083 
Ozinsky A, Underhill DM, Fontenot JD, Hajjar AM, Smith KD, Wilson CB, et al. 2000. The repertoire for pattern recognition of pathogens by the innate immune system is defined by cooperation between Toll-like receptors. Proceedings of the National Academy of Sciences of the USA, 97: 13766-13771. PMID: 11095740 DOI: 10.1073/pnas.250476497

Paxinos G, and Watson C. 2006. The rat brain in stereotaxic coordinates. Hard cover edition. Elsevier, Cambridge, MA, USA.

Quan N, Whiteside M, Kim L, and Herkenham M. 1997. Induction of inhibitory factor $\kappa B \alpha$ mRNA in the central nervous system after peripheral lipopolysaccharide administration: an in situ hybridization histochemistry study in the rat. Proceedings of the National Academy of Sciences of the USA, 94: 10985-10990. PMID: 9380746 DOI: 10.1073/pnas.94.20.10985

Roth J, and de Souza GEP. 2001. Fever induction pathways: evidence from responses to systemic or local cytokine formation. Brazilian Journal of Medical and Biological Research, 34: 301-314. PMID: 11262580 DOI: 10.1590/S0100-879X2001000300003

Rummel C. 2016. Inflammatory transcription factors as activation markers and functional readouts in immune-to-brain communication. Brain, Behavior, and Immunity, 54: 1-14. PMID: 26348582 DOI: 10.1016/j.bbi.2015.09.003

Rummel C, Sachot C, Poole S, and Luheshi GN. 2006. Circulating interleukin-6 induces fever through a STAT3-linked activation of COX-2 in the brain. American Journal of Physiology-Regulatory, Integrative and Comparative Physiology, 291: R1316-R1326. PMID: 16809483 DOI: 10.1152/ ajpregu.00301.2006

Rummel C, Gerstberger R, Roth J, and Hübschle T. 2011. Parthenolide attenuates LPS-induced fever, circulating cytokines and markers of brain inflammation in rats. Cytokine, 56: 739-748. PMID: 22004922 DOI: 10.1016/j.cyto.2011.09.022

Santos RCV, Rico MAP, Bartrons R, Pujol FV, Rosa JL, and de Oliveira JR. 2011. The transcriptional activation of the cyclooxygenase-2 gene in zymosan-activated macrophages is dependent on NF-kappa B, C/EBP, AP-1, and CRE sites. Inflammation, 34: 653-658. PMID: 21104307 DOI: $10.1007 / \mathrm{s} 10753-010-9275-3$

Saper CB, and Breder CD. 1994. The neurologic basis of fever. The New England Journal of Medicine, 330: 1880-1886. PMID: 7832832 DOI: 10.1056/NEJM199406303302609

Thangaraj P. 2016. Antipyretic activity. In Pharmacological assays of plant-based natural products. Edited by $\mathrm{P}$ Thangaraj. Springer, Cham, Switzerland. pp. 113-115.

Todd DA. 1986. A study of pyretics in rats and mice. Ph.D. thesis, University of Aberdeen, Aberdeen, UK.

Vasilache AM, Qian H, and Blomqvist A. 2015. Immune challenge by intraperitoneal administration of lipopolysaccharide directs gene expression in distinct blood-brain barrier cells toward enhanced prostaglandin $\mathrm{E}_{2}$ signaling. Brain, Behavior, and Immunity, 48: 31-41. PMID: 25678162 DOI: $10.1016 /$ j.bbi.2015.02.003

Vogel HG. 2002. Drug discovery and evaluation: pharmacological assays. Springer Science \& Business Media, Berlin Heidelberg. 
Volman TJH, Hendriks T, and Goris RJA. 2005. Zymosan-induced generalized inflammation: experimental studies into mechanisms leading to multiple organ dysfunction syndrome. Shock, 23: 291-297. PMID: 15803050 DOI: 10.1097/01.shk.0000155350.95435.28

von Asmuth EJU, Maessen JG, van der Linden CJ, and Buurman WA. 1990. Tumour necrosis factor alpha $(\mathrm{TNF}-\alpha)$ and interleukin 6 in a zymosan-induced shock model. Scandinavian Journal of Immunology, 32: 313-319. PMID: 2237286 DOI: 10.1111/j.1365-3083.1990.tb02925.x

Wilhelms DB, Kirilov M, Mirrasekhian E, Eskilsson A, Kugelberg UÖ, Klar C, et al. 2014. Deletion of prostaglandin $\mathrm{E}_{2}$ synthesizing enzymes in brain endothelial cells attenuates inflammatory fever. The Journal of Neuroscience, 34: 11684-11690. PMID: 25164664 DOI: 10.1523/JNEUROSCI. $1838-14.2014$ 